
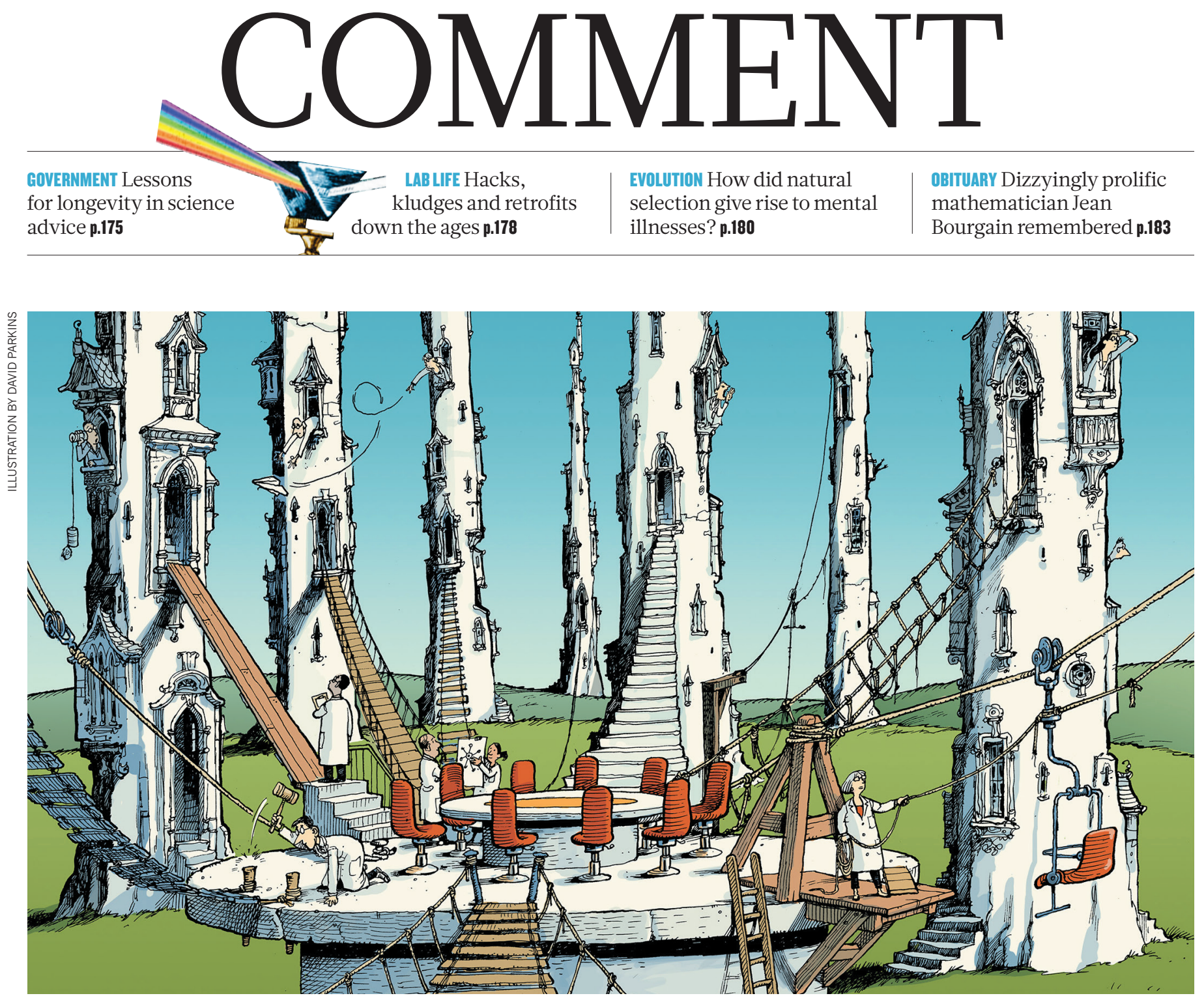

\title{
Overdue: a US advisory board for research integrity
}

Research needs an authoritative forum to hash out collective problems, argue C. K. Gunsalus, Marcia K. McNutt and colleagues.

$\mathrm{W}$ hen it comes to fostering rigour and scientific integrity, US research institutions are stuck. Working out best practice is far from straightforward, and faculty members can be resistant to top-down directives. So, on a day-to-day basis, the conventions that research groups have for documenting methods and results, conducting analyses and allocating credit are often less than optimal. At worst, they can encourage dishonesty and scandal. For example, in April 2017, Brigham and
Women's Hospital in Boston, Massachusetts, and its health-care network agreed to pay US $\$ 10$ million to settle fraud allegations in stem-cell research funding. (Researchers contest who is at fault.) The hospital has requested retractions of more than 30 papers, and a clinical trial involving more than 100 participants has been paused while data are reviewed. Resources that might have brought better medical care have been squandered.

Building a culture of quality and integrity requires conversations across the scientific enterprise. Science is a complex ecosystem of funders, journals, academic administrators, scientific societies and researchers - the latter group including principal investigators, staff scientists, postdocs and graduate students. The interests of each group conflict as often as they overlap, and interactions tend to be stratified and constrained. Institutional presidents sit on working groups with each other but not with research-integrity officers. These officers attend conferences with each other, 
but not with faculty advisers and bench scientists. Journal editors meet scientists and other editors, but not institutional officers, on whom they rely for investigation when concerns about manuscripts arise.

In the United States, a fractured, inefficient, inconsistent system has built up over the past 70 years to protect research quality and integrity. Separate and sometimes overlapping mechanisms focus on distinct areas, such as oversight of trial participants and animal subjects, data management, financial transactions and declarations of interest.

As experts who have led efforts to improve the US scientific enterprise, we know that it cannot be optimized piecemeal. To get the best returns on investment in science, we must extend the focus beyond compliance and individual conduct, to build an overarching culture of integrity and quality. What's needed is a forum for cross-cutting discussions that yield authoritative guidance and resources.

We must establish, at long last, a national research-policy board that focuses on robustness and quality. We plan to take the first steps within the next few weeks.

\section{RECURRING RECOMMENDATIONS}

The idea is not new. At least four reports from the US National Academies of Sciences, Engineering, and Medicine (NASEM) ${ }^{1-4}$, stretching back more than 25 years, have independently called for dedicated venues where leaders can have effective conversations on how best "to ensure safety, efficiency, and integrity while facilitating scientific progress and the optimal use of researchers' time"2.

Each report involved more than a dozen experts, who laboured for periods of between 18 months and 5 years to analyse issues from improving integrity to removing roadblocks for efficient research. Yet each called for strikingly similar solutions.

The first report to recommend a standing advisory board, Responsible Science ${ }^{1}$, was released in 1992; Fostering Integrity in Research $^{3}$ (which R.M.N., B.C.M. and C.K.G. helped to write) repeated that call in 2017. In 2018, NASEM called for Congress to establish a council focused specifically on earlycareer biomedical researchers ${ }^{4}$. The 2016 report, Optimizing the Nation's Investment in Academic Research ${ }^{2}$, (which L.R.F. helped to write) emphasized that, although the relationship between federal research funding agencies and academic research institutions has long been considered a partnership, there exists no formal entity through which these partners actually meet to address issues when they arise. That report recommended the creation of such an entity, a research policy board (RPB). A 2010 estimate put the cost of institutional investigations into misconduct alone at US\$110 million a year ${ }^{5}$. An RPB would cost much less and could make investigations more efficient and less necessary.

\section{TO-DO LIST \\ Policy-board priorities}

- Foster consistency and exchange of information across funders, scientists and administrators.

- Provide resources to assess research environments and boost integrity.

- Benchmark common practices across institutions and establish best practices.

- Develop guidelines and standards for misconduct investigations and formal disputes.

- Establish lists of vetted experts for external investigations.

The board should not be a government institution. The existing agencies that conduct misconduct investigations lack the remit to supply guidance across all scientific disciplines; in some cases, they have actively steered away from the trickiest issues. Also, stakeholders in research policy — including members of the public, young researchers, ethicists, researchers from regions with under-developed science systems, and research institutions - might feel less able to speak candidly to these existing agencies about ways to build a culture of integrity.

Why has no such forum been established? Part of the reason is that the role of the report contributors who make recommendations ends after they release their report. NASEM reports are often prompted by a problem or perceived crisis (for example, in 1992, Responsible Science ${ }^{1}$ followed congressional hearings held after high-profile fraud accusations and problematic investigations). By the time a report is complete, the sense of urgency to fix the situation has faded.

\section{BOARD DUTIES}

What could an RPB do? It would be a central resource to which institutional leaders and other members of the scientific enterprise could turn for assistance in creating and sustaining cultures for reliable and efficient research. That would include addressing issues related to authorship ${ }^{6}$, raising the quality of peer review, educating researchers on responsible conduct and robust analysis, streamlining research administration and assessing the research environment (see 'Policy-board priorities').

The resources and institutional memories for handling the wide range of matters on research integrity vary greatly across institutions, especially for instances of gross research misconduct, which occurs only rarely. This means that investigations into misconduct are often slow and inadequate, and collective wisdom and insights for measures that boost integrity fall by the wayside.
Anyone advising such investigations sees the same unintentional lapses occur again and again, sometimes at the same institution.

More than 200 universities and institutions focus on research in the United States. Each is trying to work out research policy alone, often haphazardly and inefficiently. Some well-funded institutions have created their own research-policy offices, each duplicating others' work. Website resources wax and wane; some federal agencies offer guidance that is specific to their own policies. A board could be both a reliable repository and a hub for the routine exchange of information, giving more institutions efficient and equitable access to what they need.

As outlined in the 2017 report $^{3}$, a board could provide just-in-time training materials, referrals to specialized and legal experts, and assistance in organizing external reviews of the components of internal investigations. More importantly, it could minimize the necessity for such processes, by serving as a collective, authoritative resource on which research leaders could call when implementing changes, including proactive assessments of the health of research environments. (Two of us have worked to develop, validate (B.C.M.) and promulgate (C.K.G.) one such assessment tool.)

The RPB would focus on robustness and quality, and should function independently of compliance and regulatory machinery. It could take on benchmarking projects, such as comparing the points that institutions include in conflict-of-interest policies. It could also take the lead in vetting or developing resources that will boost quality across all researchers, such as statistical training and checklists for rigour and transparency.

Sceptics will argue that a board is just another bureaucratic body dedicated to wasteful meetings. Many will doubt that it can instigate meaningful change, particularly given the systemic nature of the challenges to be addressed, and the pile of reports already produced on research integrity and rigour. And any effort that tackles research fraud, detrimental research practices and unintentional sloppiness risks raising hackles.

But there are examples of consortia that have successfully tackled thorny issues in research integrity. The Committee on Publication Ethics, for example, has established guidelines to handle retractions and authorship disputes, which have helped editors to navigate fraught decisions, treat researchers more fairly and buttress the literature. Groups such as the American Association for the Advancement of Science (AAAS), the Association of American Universities and the Council of Graduate Schools have also made important contributions - for instance, addressing policies and collecting benchmarking data to help institutions to gauge their performance.

Other long-established organizations 
do serve the types of function we propose for an RPB, albeit for more specific remits. InfraGard, for example, is a US non-profit organization that promotes information exchange and collaboration to protect crucial national infrastructure and key resources. The American National Standards Institute has developed voluntary consensus standards for everything from commercial kitchens to programming languages, and the Smart Grid Interoperability Panel coordinates the development of standards for electricity transmission. These bodies involve stakeholders from both public and private organizations; many started out with public funding and then established funding mechanisms, such as membership support, that allowed them to become largely self-sustaining ${ }^{4}$.

Other countries are already pursuing initiatives that could take on some of the roles we imagine for an RPB. The UK Reproducibility Network, launched last year, consists of universities that have partnered with funders and journals to establish training, infrastructure and networks that help researchers to improve experimental design and to make data available. Japan's Association for the Promotion of Research Integrity (APRIN) has issued a checklist for conducting investigations into research integrity. That was based on a 2017 US effort ${ }^{7}$, itself rooted in work done by the AAAS and various organizations in the United States three decades ago.

In Canada, the Panel on Responsible Conduct of Research, created by its three federal funding agencies, reviews institutional investigations and promotes research integrity. The Australian Research Integrity Committee, an independent body established by the Australian Research Council and the National Health and Medical Research Council, serves similar functions.
Last June, the UK Parliament issued a report that recommended establishing a national oversight committee to champion research integrity and increase transparency. Similar efforts are in place in countries including Austria, Denmark, Finland, France and Germany. If the United States does not follow suit, it could see its international scientific leadership start to fade.

We propose that the US board will not perform misconduct investigations or oversee those done by universities or other organ-

\section{"There are many perverse incentives in science."} izations. The role of the US board is to work with institutions to reduce the incidence of misconduct and other practices that damage the credibility of science. An RPB should support the specific work of journals, funders, institutional leaders and individual scientists striving for the same. It should also find ways to implement cost-effective, streamlined research processes, fairer and more-effective workforce development, and ways to eliminate sexual and gender harassment.

As a first step, the US National Academy of Sciences is convening a plenary session on the trustworthiness of science at its annual meeting in April. This will be the first opportunity for leaders of the US scientific enterprise to discuss the role of a national board for research integrity. As a follow-up, we propose a two-day meeting of stakeholders in late 2019 to determine what sort of formal entity is needed, what it should do, what kind of support it would need, and under what authorization it would operate. Invitees would include journal editors, university leaders, the US National Science Foundation and the US National Institutes of Health.
There are many perverse incentives in science, and few organized forces to counter them. A research policy board, first recommended more than 25 years ago, will benefit both science and scientists. We must act to create it now.

C. K. Gunsalus is director of the National Center for Professional and Research Ethics at the University of Illinois, UrbanaChampaign, USA. Marcia K. McNutt is president of the US National Academy of Sciences. Brian C. Martinson studies research integrity and behavioural change at the HealthPartners Institute in Bloomington, Minnesota, USA. Larry R. Faulkner is president emeritus of the University of Texas at Austin, USA. Robert M. Nerem is institute professor emeritus at the Georgia Institute of Technology, Atlanta, USA. e-mails:gunsalus@illinois.edu; mmcnutt@nas.edu

\footnotetext{
1. National Academy of Sciences, National Academy of Engineering, and Institute of Medicine. Responsible Science, Volume I: Ensuring the Integrity of the Research Process (National Academies Press, 1992)

2. National Academies of Sciences, Engineering, and Medicine. Optimizing the Nation's Investment in Academic Research (National Academies Press, 2016)

3. National Academies of Sciences, Engineering, and Medicine. Fostering Integrity in Research (National Academies Press, 2017).

4. National Academies of Sciences, Engineering, and Medicine. The Next Generation of Biomedical and Behavioral Sciences Researchers: Breaking Through (National Academies Press, 2018).

5. Michalek, A. M., Hutson, A. D., Wicher, C. P. \& Trump, D. L. PLOS Med. 7, e1000318 (2010)

6. McNutt, M. K. et al. Proc. Natl Acad. Sci. USA 115 2557-2560 (2018).

7. Gunsalus, C. K. Marcus, A. R. \& Oransky, I. J. Am. Med. Assoc. 319, 1315-1316 (2018).
}

B.C.M. declares competing financial interests; see go.nature.com/2sgqyy 5 for details.

\section{Three secrets of survival in science advice}

\section{Be impartial, humble and good value, urge Chris Tyler and Karen Akerlof.}

$\mathrm{T}$ he offices that give science advice to politicians are among the most important public bodies you've never heard of. Some nations - notably the United States and Denmark - have closed or stopped funding them. Elsewhere, these bodies are thriving: in the United Kingdom and France, for example. Differences between the healthy and the defunct hold lessons for countries that hope to improve the use of science in law-making and political debate.

Spain's national parliament, for instance, plans to open a science and technology advisory unit this summer. In the United States, hopes have been raised this past year of the return of something like the much-missed Office of Technology Assessment (OTA), shuttered in the mid-1990s. This spring, Congress is likely to consider funding for science and technology advice in its budget appropriations for the legislative branch.
Here we offer a three-step survival guide for legislative science and technology advisory bodies (LSTABs). Our recommendations are based on the key functions and factors that seem to have led to the long-term success or failure of such bodies.

\section{IN-HOUSE EXPERTISE}

Roughly $90 \%$ of legislatures lack the kind of scientific and technical advisory system that they need to be effective. Sadly, some 